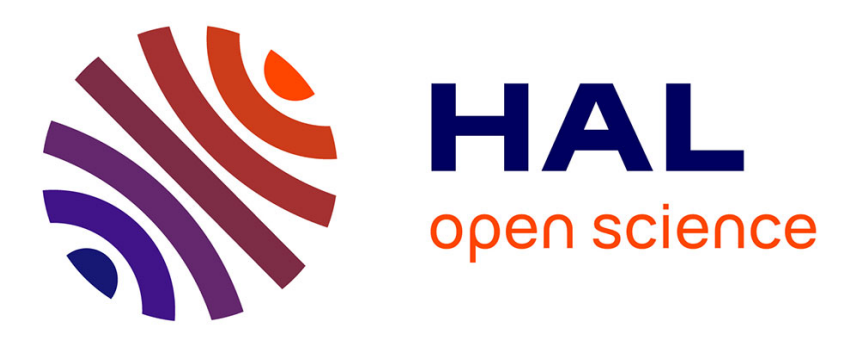

\title{
Poling influence on the mechanical properties and molecular mobility of highly piezoelectric P(VDF-TrFE) copolymer
}

Aurélien Roggero, Eric Dantras, Colette Lacabanne

\section{- To cite this version:}

Aurélien Roggero, Eric Dantras, Colette Lacabanne. Poling influence on the mechanical properties and molecular mobility of highly piezoelectric $\mathrm{P}(\mathrm{VDF}-\mathrm{TrFE})$ copolymer. Journal of Polymer Science Part B: Polymer Physics, 2017, 55 (18), pp.1414-1422. 10.1002/polb.24396 . hal-03222741

HAL Id: hal-03222741

https://hal.science/hal-03222741

Submitted on 10 May 2021

HAL is a multi-disciplinary open access archive for the deposit and dissemination of scientific research documents, whether they are published or not. The documents may come from teaching and research institutions in France or abroad, or from public or private research centers.
L'archive ouverte pluridisciplinaire HAL, est destinée au dépôt et à la diffusion de documents scientifiques de niveau recherche, publiés ou non, émanant des établissements d'enseignement et de recherche français ou étrangers, des laboratoires publics ou privés. 


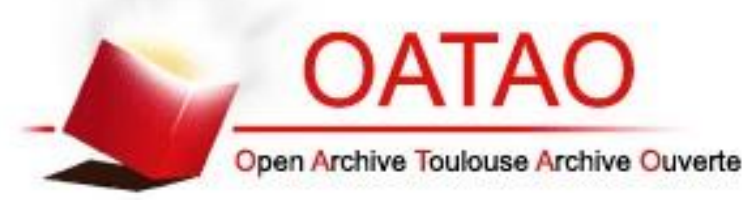

\section{Open Archive TOULOUSE Archive Ouverte (OATAO)}

OATAO is an open access repository that collects the work of Toulouse researchers and makes it freely available over the web where possible.

This is an author-deposited version published in : http://oatao.univ-toulouse.fr/ Eprints ID : 18314

To link to this article : DOI: $10.1002 /$ polb.24396

URL : http://dx.doi.org/10.1002/polb.24396

To cite this version : Roggero, Aurélien and Dantras, Eric and Lacabanne, Colette Poling influence on the mechanical properties and molecular mobility of highly piezoelectric $P(V D F-T r F E)$ copolymer. (2017) Journal of Polymer Science Part B: Polymer Physics, vol. 55 ( ${ }^{\circ}$ 18). pp. 1414-1422. ISSN 0887-6266

Any correspondence concerning this service should be sent to the repository administrator: staff-oatao@ listes-diff.inp-toulouse.fr 


\title{
Poling Influence on the Mechanical Properties and Molecular Mobility of Highly Piezoelectric P(VDF-TrFE) Copolymer
}

\author{
Aurélien Roggero, Eric Dantras (D), Colette Lacabanne \\ CIRIMAT, Université de Toulouse, Physique des Polymères, UPS, Bât. 3R1b2, 118 route de Narbonne, 31062 Toulouse Cedex 9 , \\ France \\ Correspondence to: E. Dantras (E-mail: eric.dantras@univ-tlse3.fr)
}

DOI: 10.1002/polb.24396

ABSTRACT: The calorimetric, dielectric, and mechanical responses of highly piezoelectric 70/30 P(VDF-TrFE) displaying homogenous $\mathrm{d}_{33}$ of $-19 \mathrm{pC} \mathrm{N} \mathrm{N}^{-1}$ are studied. This work aims at better understanding the influence of poling on the mechanical properties of this copolymer. To explain the one decade mechanical modulus drop observed across the Curie transition, a stiffening process of the amorphous phase due to the local electric fields in the ferroelectric crystals is proposed. In poled P(VDF-TrFE), these fields are preferentially aligned resulting in a more stable and higher modulus below the Curie transition. This hypothesis accounts for the lower dielectric signals obtained with the poled sample. Through the Curie transition, the vanishing of these local electric fields, stemming from progressive disorientation and conversion of ferroelectric crystals to paraelectric ones, releases the constraints on the amorphous phase, leading to a storage modulus drop typical of a viscoelastic transition.

KEYWORDS: piezoelectric polymer; PVDF copolymer; Curie transition; DMA; molecular dynamics
INTRODUCTION Electroactive polymers have been studied since the first evidence of piezoelectric activity in stretched and poled polyvinylidene fluoride (PVDF) by Kawai. ${ }^{1}$ Indeed, the combination of polymer mechanical properties (compared to those of the more usual piezoelectric ceramics) and piezoelectric/pyroelectric functionality pave the way to a variety of applications such as flexible sensors and actuators $^{2}$ or in the growing field of energy harvesting., ${ }^{3,4}$ Moreover, they are being used as piezoelectric matrixes for multiferroic (magnetoelectric ${ }^{5}$ for instance) composites. A recent resurgence of studies on PVDF co- and terpolymers probably originates from these prospects of practical applications. ${ }^{6-10}$

Copolymers (with tri- or tetrafluoroethylene, TrFE, and TFE) and terpolymers (with TrFE and chlorofluoroethylene, CFE) of PVDF have been developed so as to overcome the tedious and not entirely effective stretching or irradiation required for the partial conversion of the paraelectric spherulite $\alpha$ crystalline phase of solution-cast or cooled from melt PVDF into the polar $\beta$-phase exhibiting ferroelectricity at the microscopic scale. ${ }^{11}$ The introduction of a certain quantity of random $\mathrm{TrFE}(17-50 \%$ in the case of $\left.\mathrm{P}(\mathrm{VDF}-\mathrm{TrFE})^{12}\right)$, TFE or CFE groups along the main chain allows the co- and terpolymers to spontaneously crystallize in an all-trans polar phase similar to the $\beta$-phase of PVDF ${ }^{13}$
Poling these materials under high electric fields ${ }^{14}$ $\left(\sim 80 \mathrm{MV} \mathrm{m}^{-1}\right.$ ) produces preferential orientation of the ferroelectric domains, leading to electroactive properties at the macroscopic scale. To date, the PVDF family displays the highest piezoelectric $\left(d_{33}\right)$ and pyroelectric $\left(p_{3}\right)$ coupling coefficients and high dielectric permittivities allowing better poling efficiency.

The introduction of defects in the main chain allows the ferroeletric-paraelectric or Curie transition to be observed while it was found to coincide with the main melting in $\beta$ PVDF. The influence of poling on the Curie transition of the copolymers has been studied mainly by means of crystallographic, calorimetric, and dielectric techniques. ${ }^{15-19}$ While the mechanical response of $\mathrm{P}(\mathrm{VDF}-\mathrm{TrFE})$ have been studied, ${ }^{10,20-23}$ it was for the most part analyzed from a relaxation point of view and little focus was made on the mechanical manifestation of the Curie transition or on the influence of poling on the mechanical properties.

This study aims at assessing the impact of saturated homogeneous polarization on the mechanical response of 70/30 P(VDF-TrFE) over a wide temperature range. The analysis of the transitions and relaxations related to molecular mobility should provide comprehension elements. 


\section{EXPERIMENTAL}

\section{Studied Material}

The studied material is a $50-\mu \mathrm{m}$-thick poled $70 / 30 \mathrm{P}(\mathrm{VDF}$ TrFE) film supplied from Piezotech. According to the datasheet, the film was enducted from solution then poled following the cyclic Bauer process. ${ }^{24}$ A consistently high piezoelectric coefficient of $-19 \mathrm{pC} \mathrm{N} \mathrm{N}^{-1}$ was measured on the entire film by means of a PM200 piezometer manufactured by Piezotest applying a $0.25 \mathrm{~N}$ force at $110 \mathrm{~Hz}$.

\section{Differential Scanning Calorimetry}

Differential scanning calorimetry (DSC) measurements were performed on a DSC 2920 manufactured by TA Instruments. The apparatus was calibrated in both temperature and enthalpy using indium, tin, and mercury standards. Sample bits ( $10 \mathrm{mg}$ mass) were encapsulated in sealed aluminum pans. Temperature ramps of $20{ }^{\circ} \mathrm{C} \mathrm{min}^{-1}$ were performed under helium, in the range $\left(-150,200{ }^{\circ} \mathrm{C}\right)$.

\section{Dynamic Mechanical Analysis}

Dynamic mechanical analysis (DMA) measurements were performed on an ARES G2 manufactured by TA Instruments. The films were studied in the linear tension configuration through $3{ }^{\circ} \mathrm{C} \min ^{-1}$ ramps under a heated nitrogen flux. A $0.02 \%$ dynamic tensile strain, at the angular frequency of $6.3 \mathrm{rad} \mathrm{s}^{-1}$, was applied to the samples, allowing the determination of the complex tensile modulus $E^{*}$ (eq 1 ).

$$
E^{*}(\omega, T)=E^{\prime}(\omega, T)+i E^{\prime \prime}(\omega, T)
$$

where $E^{\prime}$ and $E^{\prime \prime}$ are the storage and loss tensile moduli, respectively.

Because of the thinness of the samples $(50 \mu \mathrm{m})$, they tended to irreversibly flow and break when heated through the Curie transition under static axial forces as low as $2 \mathrm{~N}$. Two measures were taken to cope with this problem. First, to increase sample thickness, two poled samples were stacked together, oriented in the same direction with respect to poling, and "soldered" using a few drops of acetone on the extremities where the sample would be held in the clamping jaws (taking care not to modify the material in between the jaws). Second, contrary to the usual way of performing dynamic elongation tests, no static axial force was applied in between the measurements. This prevented irreversible sample deformation but induced a noisier signal which was filtered using a 30-point quadratic Savitzky-Golay filter.

\section{Dynamic Dielectric Spectroscopy}

Dynamic dielectric spectroscopy (DDS) measurements were performed isothermally in the frequency range $\left(10^{-2} ; 10^{6}\right.$ $\mathrm{Hz}$ ) using a Novocontrol BDS 4000 impedance analyzer. The samples were placed between gold-plated stainlesssteel electrodes (30 $\mathrm{mm}$ diameter). A heated nitrogen flux allowed temperature control over the range $(-150$; $\left.150{ }^{\circ} \mathrm{C}\right)$.

The relative complex dielectric permittivity (eq 2) was calculated from the measured impedance values $Z^{*}$.

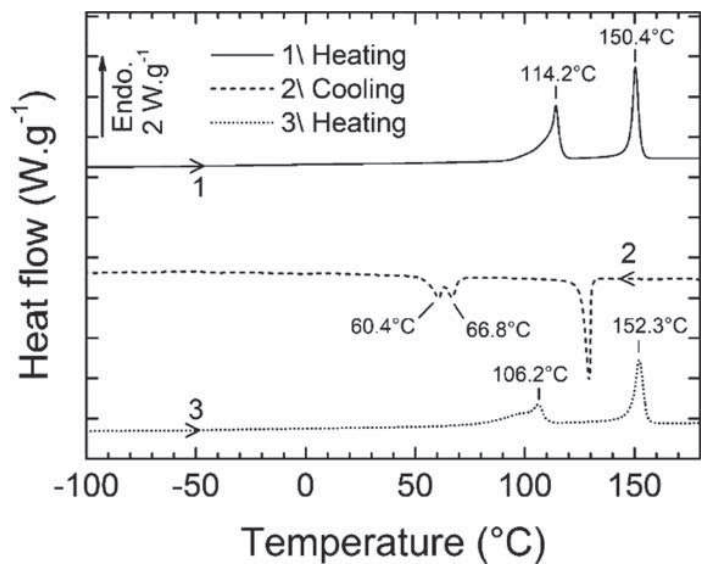

FIGURE 1 Consecutive differential scanning calorimetry thermograms of initially poled $\mathrm{P}(\mathrm{VDF}-\mathrm{TrFE})$ performed at $20^{\circ} \mathrm{C} \mathrm{min}^{-1}$.

$$
\varepsilon^{*}(\omega)=\varepsilon^{\prime}(\omega)-i \varepsilon^{\prime \prime}(\omega)=\frac{1}{i \omega C_{0} Z^{*}(\omega)}
$$

where $\varepsilon^{\prime}$ and $\varepsilon^{\prime \prime}$ are the real and imaginary components of the complex dielectric permittivity, $\omega$ is the angular frequency, and $C_{0}$ is the capacitance of the configuration filled with air instead of the sample.

The Havriliak-Negami parametric equation (eq 3) was used to fit the experimental data. ${ }^{25}$

$$
\varepsilon^{*}=\varepsilon_{\infty}+\frac{\varepsilon_{\mathrm{s}}-\varepsilon_{\infty}}{\left(1+\left(i \omega \tau_{\mathrm{H}-\mathrm{N}}\right)^{\alpha_{\mathrm{H}-\mathrm{N}}}\right)^{\beta_{\mathrm{H}-\mathrm{N}}}}
$$

where $\varepsilon_{\infty}$ and $\varepsilon_{s}$, respectively, are the high- and lowfrequency limits of the relative permittivity, $\omega$ is the angular frequency, $\tau_{\mathrm{H}-\mathrm{N}}$ is the mean relaxation time of the dipole distribution, $\alpha_{\mathrm{H}-\mathrm{N}}$ and $\beta_{\mathrm{H}-\mathrm{N}}$ are adjustable fit parameters, respectively, linked to the width and symmetry of the distribution.

\section{RESULTS AND DISCUSSION}

Poling Influence on the Physical Structure

Successive DSC scans of an initially poled 70/30 P(VDFTrFE) sample are represented in Figure 1.

The heating ramps (1) and (3) both feature two endothermic events. The first one, respectively situated at $T_{\mathrm{c}}=114.2{ }^{\circ} \mathrm{C}$ and $106.1{ }^{\circ} \mathrm{C}$ on the thermograms 1 and 3 , is associated with the ferro-to-paraelectric or Curie transition. ${ }^{26}$ It is bimodal and, following the studies by Lovinger et al. ${ }^{27}$ Kim and $\mathrm{Kim}^{28}$ or Bargain et al., ${ }^{7}$ for instance, it can be attributed to the coexistence of a perfect ferroelectric all-trans (high-temperature component) phase and a defective ferroelectric phase containing gauche conformational defects (low-temperature component). Long range all-trans configuration in the crystallites is impossible above $T_{\mathrm{c}}$, resulting in the loss of the ferroelectric property. The second peak, respectively occurring at $T_{\mathrm{f}}=150.4{ }^{\circ} \mathrm{C}$ and $152.3{ }^{\circ} \mathrm{C}$, corresponds to the melting of the paraelectric crystalline phase. The cooling 
ramp (2) features two exothermic peaks. The first one occurring at $129.4{ }^{\circ} \mathrm{C}$ is associated with the crystallization process. The second peak is bimodal $\left(66.8{ }^{\circ} \mathrm{C}\right.$ and $\left.60.4{ }^{\circ} \mathrm{C}\right)$ and corresponds to the para-to-ferroelectric transition, with the formation of the perfect and defective ferroelectric phases. The large hysteresis of the Curie transition (about $50{ }^{\circ} \mathrm{C}$ ) has been reported in many DSC studies and considered as an indicator of the ferroelectric-to-paralectric transition. ${ }^{29-31}$

Poling has several influences on the physical transitions of 70/ 30 P(VDF-TrFE). First, a $8{ }^{\circ} \mathrm{C}$-shift of the Curie temperature toward the high temperatures is observed as a consequence of poling, in good agreement with literature. ${ }^{16,32,33}$ Second, the enthalpy associated with the Curie transition is approximately $33 \%$ higher in the case of the poled sample: $28 \mathrm{~J} \mathrm{~g}^{-1}$, (Fig. 1, ramp $1 \backslash$ ), as opposed to $18 \mathrm{~J} \mathrm{~g}^{-1}$ in the case of the depoled sample, (Fig. 1, ramp 3\). These values are also in good agreement with recent literature. ${ }^{7}$ Last, the melt temperature of the depoled material is $2{ }^{\circ} \mathrm{C}$ higher than that of the poled one.

The difference in the Curie enthalpies indicates that the ferroelectric phase of the poled material is more stable than in the depoled one, as more energy and higher temperatures are needed for the Curie transition to occur. This increased stability can be ascribed to a poling-induced ejection of conformational defects from the ferroelectric phase, resulting in an increase of the high-temperature component of the Curie endotherm at the expense of the defective ferroelectric phase that only appears as a slight shoulder on the poled sample thermogram. From a practical point of view, an additional poling-induced cohesive enthalpy $\Delta H_{\text {poling }}$ may be defined so that the total enthalpy of the Curie transition in the poled material is the sum defined in eq 4

$$
\Delta H_{\text {Curie }}^{\text {poled sample }}=\Delta H_{\text {Curie }}^{\text {unpoled }}+\Delta H_{\text {poling }}
$$

There is a limit to a precise estimate of $\Delta H_{\text {poling }}$ from Figure 1 , which is the degree of crystallinity $\chi_{c}$ of the material. It depends on the thermal history of the sample and while it is controlled for the depoled sample $\left(-20{ }^{\circ} \mathrm{C} \mathrm{min}^{-1}\right.$ from the melt, see ramp (2) in Fig. 1), it is unknown for the commercial poled sample. However, the manufacturing process involves the dissolution in a solvent (not specified in the datasheet) and enduction on a metal plate prior to poling. To estimate the degree of crystallinity of the commercial sample without the influence of poling on the enthalpy of the Curie transition, some of it was dissolved in acetone and let to sit at room temperature until the solvent had completely evaporated. Thus obtained solvent-cast sample is believed to have a thermal history similar to the commercial sample prior to the poling step (aside from storage time), and therefore, a similar degree of crystallinity $\chi_{c}$, which can be estimated thanks to eq $5 .^{34}$ Its DSC traces are displayed in Figure 2.

$$
\chi_{\mathrm{c}}(\%)=\frac{\Delta H_{\text {melt }}+\Delta H_{\text {Curie }}}{\Delta H_{\infty}} \times 100
$$

where $\Delta H_{\text {melt }}$ is the enthalpy of fusion, $\Delta H_{\text {Curie }}$ is the enthalpy of the Curie transition, and $\Delta H_{\infty}$ is the theoretical enthalpy of fusion of $100 \%$ crystalline $70 / 30$ P(VDF-TrFE).

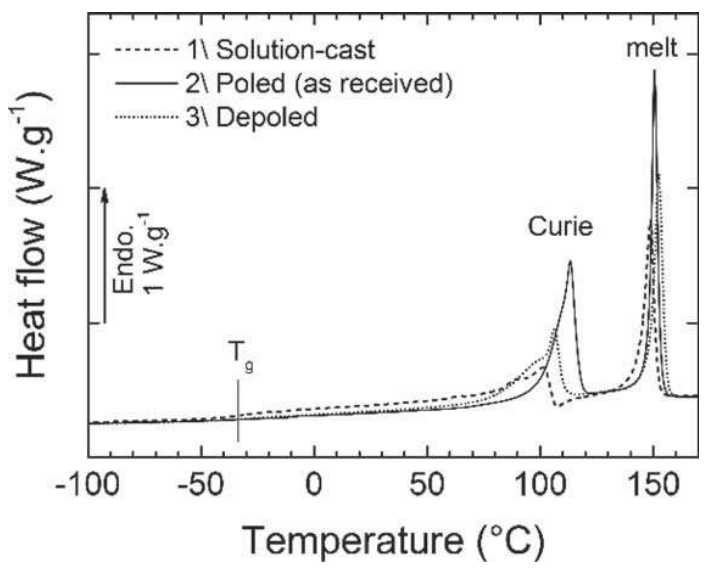

FIGURE 2 Differential scanning calorimetry thermograms of $1 \backslash$ a solvent-cast unpoled sample, $2 \backslash$ a poled sample (as received, equivalent to ramp $1 \backslash$ in Fig. 1), and $3 \backslash$ the depoled sample (second heating of the poled sample, equivalent to ramp $3 \backslash$ in Fig. 1).

$\Delta H_{\text {melt }}$ and $\Delta H_{\text {Curie }}$ are determined from DSC measurements by integrating the corresponding peaks and dividing the areas $\left(\mathrm{W} \mathrm{g}^{-1} \mathrm{~K}^{-1}\right)$ by the ramp rate $\left(\mathrm{K} \mathrm{s}^{-1}\right)$. These values are summarized in Table $1 . \Delta H_{\infty}$ of $70 / 30 \mathrm{P}(\mathrm{VDF}-\mathrm{TrFE})$ can be estimated by weighing the respective values of fully crystalline PVDF (25 cal/g $=106.6 \mathrm{~J} \mathrm{~g}^{-1}$ from ref. 35) and PTrFE (1300 $\mathrm{cal} \mathrm{mol}^{-1}=66.3 \mathrm{~J} \mathrm{~g}^{-1}$ from ref. 26), leading to a value of $97.1 \mathrm{~J} \mathrm{~g}^{-1}$.

This leads to a crystallinity of $40 \%$ for the solvent-cast sample (Fig. 2, ramp $1 \backslash$ ) and $46 \%$ for the depoled sample (Figs. 1 and 2, ramp $3 \backslash$ ). This difference indicates that solutioncasting leads to lower crystallinity than cooling from the melt at $20{ }^{\circ} \mathrm{C} \min ^{-1}$, which eases the observation of the glass transition (Fig. 2, ramp $1 \backslash$ ). Performing the same calculation on the poled sample (Fig. 2, ramp $2 \backslash$ ) would lead to an apparent crystallinity of $56 \%$, but poling at room temperature is not expected to induce such a variation in the material's physical structure, especially given the fact that $\Delta H_{\text {melt }}$ remains almost constant (Table 1). Bargain et al., by performing X-ray scattering measurements, indeed evidenced that absolute crystallinity of P(VDF-TrFE) is not affected by poling, ${ }^{7}$ therefore making the use of eq 5 to estimate the crystallinity of poled samples questionable. Similar doubts were also expressed by Whiter et al. ${ }^{36}$

According to the manufacturer, the as-received poled sample was enducted and poled at room temperature, and in the case that no annealing procedure was applied, its crystallinity can be estimated close to $40 \%$, supporting the existence of a poling-induced cohesive enthalpy $\Delta H_{\text {poling }}$ of $\sim 14 \mathrm{~J} \mathrm{~g}^{-1}$. Such enthalpy is approximately equal to the Curie enthalpy of the solvent-cast unpoled sample (the area of the Curie peak was doubled with poling, see Fig. 2). $\Delta H_{\text {poling }}$ is thus expected to be quantitatively related to the reduction of gauche conformational defects in favor of longer trans sequences in the ferroelectric phase, leading to higher structural order. ${ }^{16}$ 
TABLE 1 Enthalpies Associated With the Curie and Melting Endotherms of Poled (As-Received), Depoled, and Solution-Cast in the Lab Samples, Along With Apparent Crystallinity

\begin{tabular}{lllc}
\hline Sample & $\Delta H_{\text {Curie }}\left(\mathrm{J} \mathrm{g}^{-1}\right)$ & $\Delta H_{\text {melt }}\left(\mathrm{J} \mathrm{g}^{-1}\right)$ & Apparent $\chi_{\mathrm{c}}(\%)$ \\
Poled solution-cast (as-received) & $28 \pm 1$ & $27 \pm 1$ & 56 \\
Cooled from melt $\left(20^{\circ} \mathrm{C} \mathrm{min}^{-1}\right)$ & $18 \pm 1$ & $27 \pm 1$ & 46 \\
Solution-cast in the lab & $14 \pm 1$ & $25 \pm 1$ & 40
\end{tabular}

Finally, the $2{ }^{\circ} \mathrm{C}$ higher melt temperature in the depoled sample is probably linked to the increase in crystallinity induced by cooling from the melt as opposed to the solution-cast initial state of the poled sample.

\section{Dielectric Relaxation and Molecular Mobility Dielectric Manifestation of the Curie Transition}

Dynamic dielectric spectroscopy was used on a poled sample in the range $\left(20,120^{\circ} \mathrm{C}\right)$. Similar to the DSC scans, three successive $7{ }^{\circ} \mathrm{C} \min ^{-1}$ temperature ramps (heating, cooling, heating) were applied to the sample while the complex dielectric permittivity was continually being measured at $1 \mathrm{kHz}$. The real component $\varepsilon^{\prime}(\mathrm{T})$ of $\varepsilon^{*}$ is displayed with respect to temperature in Figure 3.

The large hysteresis of the dielectric manifestation of the Curie transition is observed in Figure 3, consistently with literature $^{31,37}$ and DSC measurements. Below $T_{c}$, the poled sample displays a real permittivity approximately two times smaller than the depoled one. A similar decrease in permittivity upon poling was recently evidenced by Whiter et al. ${ }^{36}$

The dielectric manifestation of the Curie transition in the poled sample is observed approximately $10{ }^{\circ} \mathrm{C}$ higher than in the depoled sample. Davis et al. similarly evidenced a $10{ }^{\circ} \mathrm{C}$ increase in the Curie temperature as well as a decrease of $\varepsilon^{\prime}$ in the range $\left(-50,90^{\circ} \mathrm{C}\right)$ subsequently to poling in $52 / 48$ $\mathrm{P}(\mathrm{VDF}-\mathrm{TrFE}){ }^{18}$ Legrand also evidenced a very similar behavior with $70 / 30 \mathrm{P}(\mathrm{VDF}-\mathrm{TrFE}){ }^{19}$ Moreover, the associated

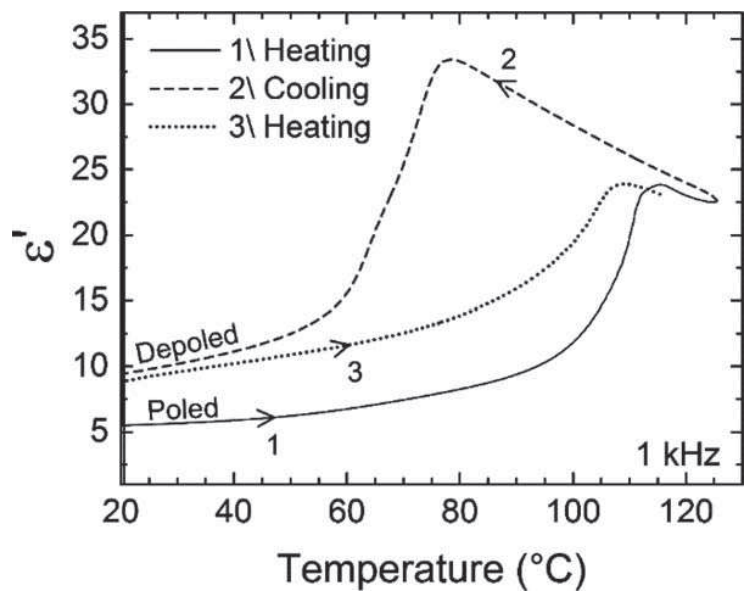

FIGURE 3 Evolution of the real permittivity of initially poled P(VDF-TrFE) when heated and cooled through the Curie transition (three consecutive $7{ }^{\circ} \mathrm{C} \mathrm{min}^{-1}$ temperature ramps). permittivity step $\Delta \varepsilon^{\prime}$ is larger, even though $\varepsilon^{\prime}$ is lower in the poled sample below $T_{\mathrm{c}}$

All these dielectric results are consistent with the concept of a cohesive contribution stemming from the poling-induced perfection of the ferroelectric phase, associated with the additional enthalpy of cohesion estimated from DSC.

\section{Poling Influence on Molecular Mobility}

To analyze the influence of poling on the molecular mobilities of P(VDF-TrFE), the diffusive processes (put to light by the imaginary component $\varepsilon^{\prime \prime}$ of $\varepsilon^{*}$ ) are represented on a 3D relaxation map for a poled sample in Figure 4 and for a depoled sample Figure 5, the latter consisting of the second pass on the same sample, $8 \mathrm{~h}$ after the first one.

These two maps feature four common dielectric events: the $\gamma, \beta, \alpha_{c}$ relaxation modes and the manifestation of the Curie transition which is independent of frequency, confirming that it is a first-order transition. ${ }^{38}$

In the vicinity of $-100{ }^{\circ} \mathrm{C}$, the low-amplitude widespread $\gamma$ mode has been ascribed to the mobility of short segments of frozen backbone chain ${ }^{23}$ or density fluctuation due to local order in the amorphous phase. ${ }^{30}$ Both these interpretations

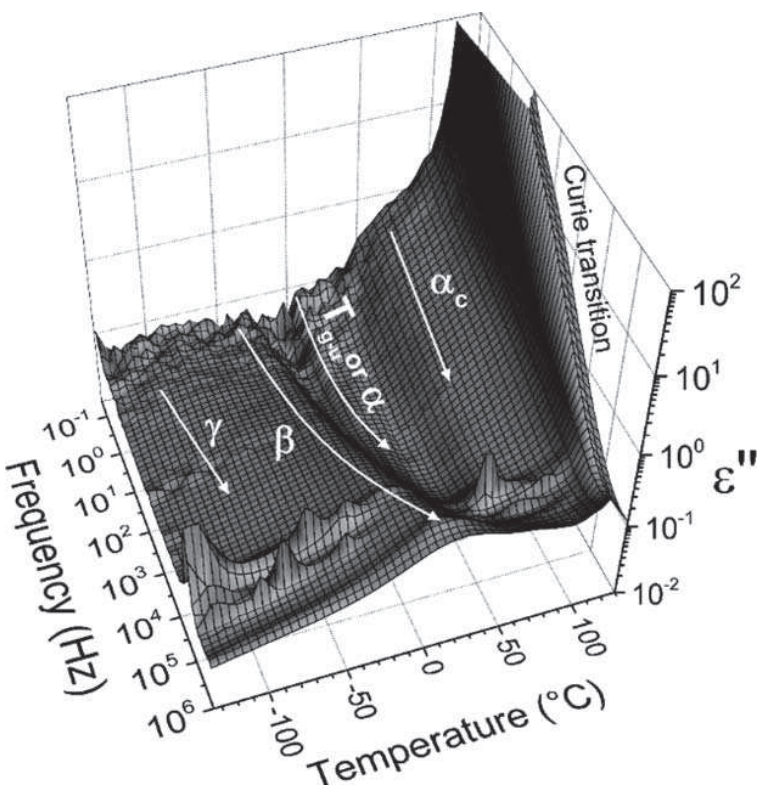

FIGURE 4 Dielectric relaxation map of initially poled 70/30 $\mathrm{P}$ (VDF-TrFE) as measured by means of dynamic dielectric spectroscopy. 


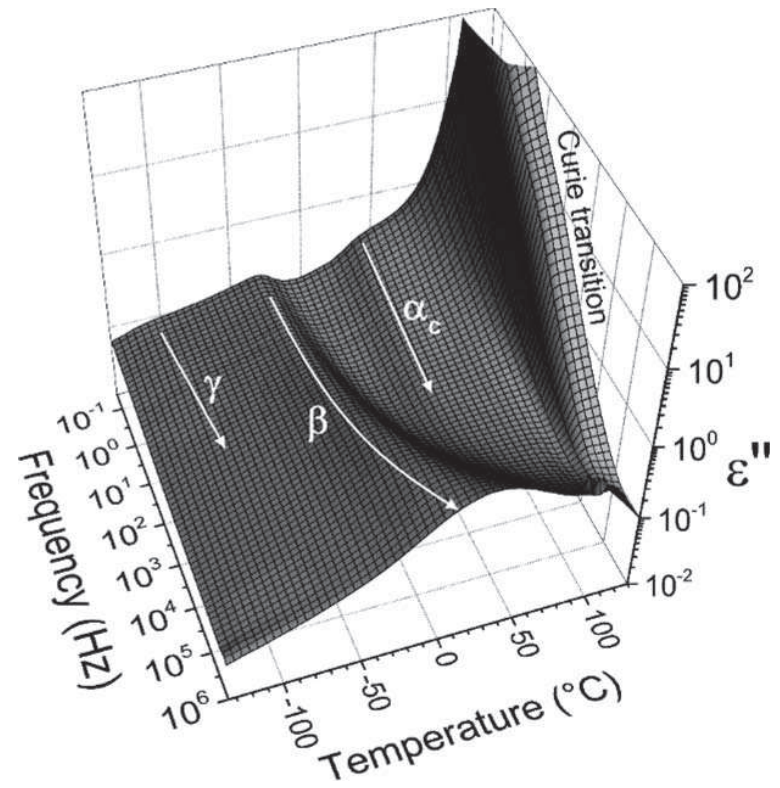

FIGURE 5 Dielectric relaxation map of depoled 70/30 P(VDFTrFE) (second pass of Fig. 4 after $8 \mathrm{~h}$ at room temperature) as measured by means of dynamic dielectric spectroscopy.

seem rather vague in terms of molecular origin for the $\gamma$ mode because the involved relaxing entities are not defined nor located. The main $\beta$-mode corresponds to the dielectric manifestation of the glass transition, related to microBrownian motions within the amorphous phase. ${ }^{23,39}$

The molecular origin of the third common mode, noted $\alpha_{c}$, observed in the vicinity of $50{ }^{\circ} \mathrm{C}$, is still a matter of debate. This relaxation was first observed in PVDF, and some authors ascribed it to molecular motions of defects within the bulk of the crystallites. ${ }^{40,41}$ Later, the $\alpha_{c}$ relaxation was shown to be highly dependent on the thermal history of the material, ${ }^{42}$ especially after annealing between $T_{\mathrm{g}}$ and $T_{\mathrm{m}}$.

Analysis of the pyroelectric currents ${ }^{43-45}$ and DSC traces (occurrence of a small endotherm) ${ }^{31,42,44}$ suggests the occurrence of the $\alpha_{c}$ relaxation in the vicinity of $50-60{ }^{\circ} \mathrm{C}$ for PVDF and $\mathrm{P}(\mathrm{VDF}-\mathrm{TrFE})$ is linked to annealing at room temperature, that is the general storage conditions. This relaxation is not observed during a consecutive second pass but is recovered when annealed again. The study by Neidhöfer et al. evidenced that the endotherm associated with the $\alpha_{c}$ relaxation in DSC traces occurred approximately $10{ }^{\circ} \mathrm{C}$ above the annealing temperature, and that its enthalpy was proportional to the logarithm of annealing time. ${ }^{44}$ These authors made a parallel with the secondary crystallization processes observed by Marand et al. $^{46}$ in PolyEtherEtherKetone notably, and suggested that a similar phenomenon was taking place in PVDF regardless of the crystalline phase being $\alpha$ or $\beta$. On another hand, Teyssèdre et al. ascribed the $\alpha_{c}$ relaxation to the formation of an "ordered layer" at the amorphous-crystal interfaces. ${ }^{45}$ From a simplified perspective of the $\alpha_{c}$ molecular origin, the concepts of an unperfect secondary crystalline phase and an ordered amorphous phase at the surface of the crystalline phase seem very similar.

In the case of our 70/30 P(VDF-TrFE) samples, the quasifrequency independent $\alpha_{c}$-mode (Figs. 4 and 5) combined with the reported occurrence of endotherms in DSC that are erased and formed again upon annealing between $T_{\mathrm{g}}$ and $T_{\mathrm{m}}$ concur toward the hypothesis of the formation of secondary disordered crystals. The association of such behaviors with the mobility of an amorphous phase, even constrained, is counterintuitive.

This brings us to the major differences between the dielectric relaxation maps of the poled and depoled samples (Figs. 4 and 5). Isochronal $\varepsilon^{\prime}$ and $\varepsilon^{\prime \prime}$ thermograms at $10 \mathrm{~Hz}$ have been represented in Figure 6. This frequency was chosen to avoid the noise at the lower frequencies and the vanishing of the relaxations at higher frequencies.

Similar to the observation made on Figure 3, the first difference is the lower signal/noise ratio for the poled sample, stemming from globally lower $\varepsilon^{\prime}$ and $\varepsilon^{\prime}$ measured below $T_{\mathrm{c}}$. This is ascribed to the influence of oriented local electric fields in the crystalline phase, which "elastically" restrains the amplitude of dipole motions.

The second difference is an additional small dielectric relaxation located in the vicinity of $10{ }^{\circ} \mathrm{C}$ for the poled sample, called $\alpha$ or $T_{\mathrm{g}-\mathrm{u}}$ (upper component of $T_{\mathrm{g}}$ ) in the literature related to $\mathrm{PVDF}^{45,47}$ It has been ascribed to the dielectric relaxation of a constrained amorphous phase in the vicinity of the crystalline phase. ${ }^{43,45}$ The increase of the fraction of constrained amorphous phase in the poled sample seems rational because of higher oriented local electric fields. Moreover, in the depoled case, the $\alpha$ and the $\alpha_{c}$ relaxations could

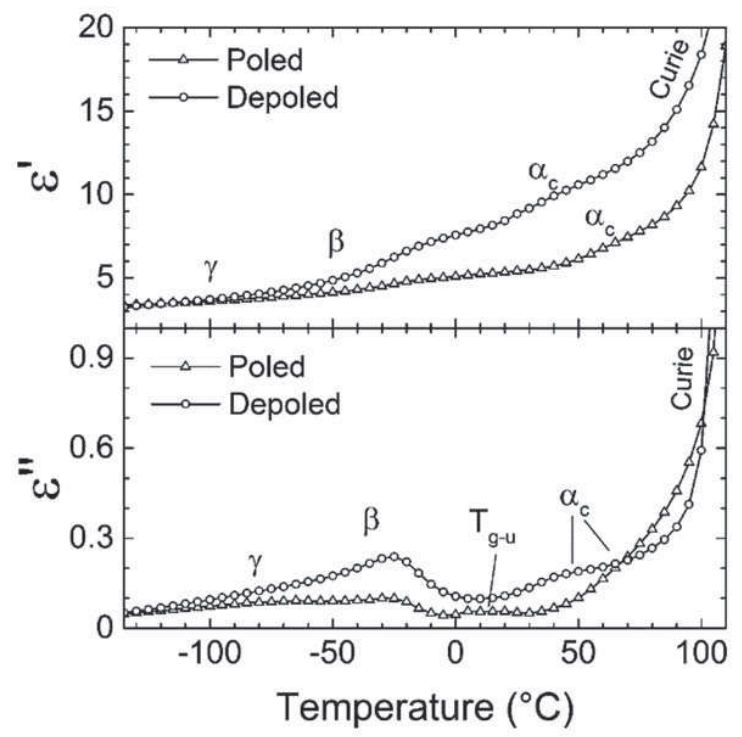

FIGURE 6 Isochronal thermograms of relative permittivity and dielectric losses in the poled and depoled samples as measured by means of dynamic dielectric spectroscopy at $10 \mathrm{~Hz}$. 


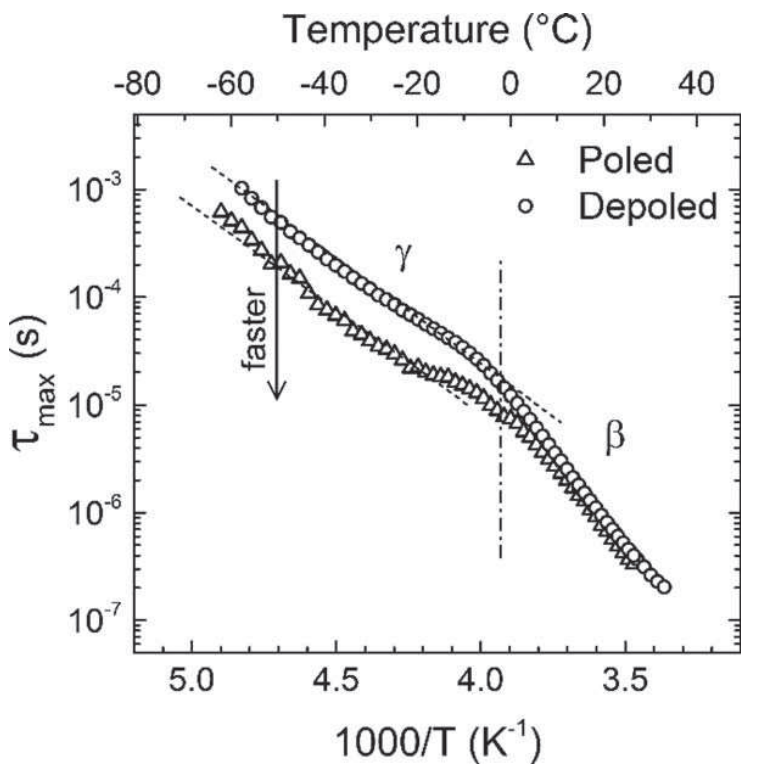

FIGURE 7 Arrhenius diagram of the dipole relaxation times obtained by fitting the dynamic dielectric spectroscopy isothermal spectra with the Havriliak-Negami equation (the dashed lines are represented as guides for the eye).

appear as a single spread out peak due to a lack of resolution. The shift toward higher temperatures of the $\alpha_{c}$ relaxation indeed favors the observation of two separate peaks in the poled case.

Using the Havriliak-Negami parametric equation (eq 3), the isothermal DDS spectra in the temperature range $(-60,30$ ${ }^{\circ} \mathrm{C}$ ) were fitted so as to extract the mean dipole relaxation times of the $\gamma$ - and $\beta$-modes represented in the Arrhenius plot of Figure 7. Contrary to the $\gamma$ - and $\beta$-modes, the $\alpha_{c^{-}}$mode could not be fitted due to it being frequency independent and mixed with the onset of the Curie transition. Moreover, bearing in mind it is probably associated with the melting of secondary crystals, it is arguable whether it should be fitted at all. The $T_{\text {g-u }}$ mode could not be fitted either due the weak signals obtained.

The relaxation times of both the poled and depoled samples display two main regimes on either side of $\sim 5{ }^{\circ} \mathrm{C}$, which correspond to the $\gamma$ and $\beta$-modes. These two modes merge at the intermediate temperatures, resulting in a continuity of the fits seen in Figure 7, even though these processes do not involve the same relaxing entities.

While the $\beta$-mode is not significantly affected by poling, the relaxation times associated with the $\gamma$-mode of the poled sample are about $60 \%$ shorter than those of the depoled sample. Thus, on one hand, the delocalized mobility of the free amorphous phase (the dielectric manifestation of the glass transition) is unaffected by the poling. On the other hand, the local mobility associated with the g-mode relaxes faster as a result of polarization. While the molecular origin of this mode is not identified, this result suggests that it is correlated with the crystalline phase, probably in its close proximity.

With regard to the $\alpha_{c}$ relaxation, dielectric losses in Figure 6 show that the amplitude of the $\gamma$ and $\beta$ relaxations are larger in the depoled sample. Bearing in mind that the relaxation times (Fig. 7) for the $\beta$-mode are mostly unaffected by poling, this means that the proportion of free amorphous phase responding in DDS is reduced by poling but its dynamics remain the same. A simple scenario accounting for these observations on the poling influence would be that as local electric fields are more and more oriented in the same direction due to the poling process, a larger part of the true amorphous phase is influenced by them, reducing its dielectric response ( $\beta$-mode and associated permittivity step).

The $\alpha_{\mathrm{c}}$-mode appears at higher temperatures (around 70-80 ${ }^{\circ} \mathrm{C}$ versus $40-50{ }^{\circ} \mathrm{C}$ for the depoled sample) as a shoulder of the Curie transition, and with a larger amplitude in the poled sample. This behavior is consistent with the studies by Neidhöfer et al. ${ }^{44}$ and Teyssèdre et al $^{45}$ that showed an increase in the pyroelectric current associated with the $\alpha_{c}$ relaxation of $\beta$-PVDF upon poling the sample, erased after the first pass. In the context of secondary crystallization processes when annealed between $T_{\mathrm{g}}$ and $T_{\mathrm{c}}$, the higher local electric fields in the poled sample are thought to ease and speed up the ordering process.

The shift to higher temperatures probably results from the combination of poling and very long (potentially months) storage times of the commercial sample at room temperature prior to the experiments. In comparison, the sample has only been annealed for $8 \mathrm{~h}$ at room temperature between the two DDS passes (Figs. 4 and 5). The $\alpha_{c}$-peak position for the depoled sample (Fig. 6) is consistent with such annealing time at room temperature. ${ }^{44}$

\section{Dynamic Mechanical Analysis}

While the mechanical manifestation of the Curie transition was experimentally evidenced by several other authors, ${ }^{10,20,21}$ the influence of poling on this process has not been studied. This is probably due to the conflicting needs for thin samples, to allow for high poling fields, and thick samples to perform mechanical testing in the most widely used configurations. The linear tension configuration, consisting in applying a dynamic stress along the vertical axis (longitudinal to the sample) and measuring the induced strain so as to determine the complex tensile modulus $E^{*}$, is the most suitable for the analysis of thin polymer films.

\section{Mechanical Relaxations}

In Figure 8 are represented two $3{ }^{\circ} \mathrm{C} \mathrm{min}^{-1}$ DMA heating ramps $(0.02 \%, 1 \mathrm{~Hz})$ obtained in this configuration with an initially poled 70/30 P(VDF-TrFE) sample. At the end of the first ramp, the sample was maintained $3 \mathrm{~min}$ at $125{ }^{\circ} \mathrm{C}$ to release the dipole orientation generated by poling. The cooling ramp between the two heating ramps, also performed at $3{ }^{\circ} \mathrm{C} \mathrm{min}^{-1}$, is not represented for the sake of clarity. The sample is considered depoled during the second heating 


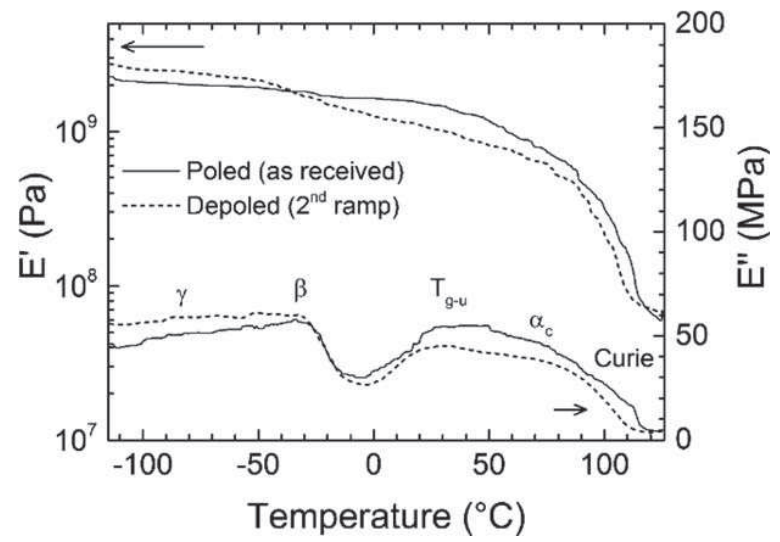

FIGURE 8 Storage $\left(E^{\prime}\right)$ and loss $\left(E^{\prime \prime}\right)$ tensile moduli of poled and depoled P(VDF-TrFE) as determined by means of dynamic mechanical analysis $\left(3^{\circ} \mathrm{C} \mathrm{min}^{-1}\right.$ heating ramps).

ramp but in order not to change the sample clamping setup, the $d_{33}$ was measured after the second heating ramp, at $0 \pm 0.5 \mathrm{pC} \mathrm{N}^{-1}$.

Mechanical measurements are sensitive to the variety of molecular dynamics in P(VDF-TrFE) as they evidence, in both the poled and depoled materials, the four relaxations and the manifestation of the Curie transition (indicated along the loss modulus in Fig. 8). In particular, the $T_{\mathrm{g}-\mathrm{u}}$ mode around $20-30{ }^{\circ} \mathrm{C}$, hardly noticeable on the DDS dielectric relaxation map of the poled sample (Fig. 4), is now more prominent than the $\alpha_{c}$ relaxation.

The mechanical losses below the $\beta$-mode are hindered by the poling process, similarly to the dielectric results, while those of the convoluted $\alpha$ and $\alpha_{c}$ relaxations are higher in the poled sample.

\section{Amorphous Phase Stiffening Due to Local Electric Fields in the Ferroelectric Crystals}

Figure 9 focuses on the mechanical manifestation of the Curie transition of three consecutive heating/cooling/heating ramps between -115 and $125{ }^{\circ} \mathrm{C}$. The associated dimension change relative to the length $L_{0}$ of the poled sample at $30{ }^{\circ} \mathrm{C}$ is displayed in the inset of Figure 9.

The Curie transition is accompanied with a steep one decade-drop in storage modulus in the vicinity of $110{ }^{\circ} \mathrm{C}$. If this behavior has been reported in literature, ${ }^{7,10,20,21}$ it has not focused a lot of attention except for some authors who suggested that it was mainly due to the transition from a ferroelectric crystalline phase to a supposedly much lower modulus paraelectric phase (by means of a mixing law through the Curie transition). ${ }^{21,48}$

We believe that the striking feature of the mechanical Curie transition resides in the region located between the viscoelastic and Curie transitions rather than in the modulus drop itself. On one hand, the storage modulus on the rubbery plateau is unusually high $(\sim 1 \mathrm{GPa})$ while on the other hand, it becomes consistent with a rubbery plateau above $T_{\mathrm{c}}$. From that perspective, the Curie transition manifests mechanically in a very similar way to a viscoelastic transition, except $130{ }^{\circ} \mathrm{C}$ higher. As a comparison, the shear storage modulus of $40 \%$ crystalline PET (similar high crystallinity to that of the studied 70/30 P(VDF-TrFE)) drops from $\sim 2$ to $\sim 0.1 \mathrm{GPa}$ across the viscoelastic transition. ${ }^{49}$

The local electric fields existing in the ferroelectric crystalline phase are believed to constrain a significant part of the free amorphous phase, producing a dipolar "glassy-like" state until the occurrence of the Curie transition and the subsequent disappearance of the local electric fields. Above this transition, the storage modulus then drops towards the 100 $\mathrm{MPa}$ range typical of a rubbery plateau. Upon the cooling ramp, the modulus returns to its ferroelectric-state value after the para-to-ferroelectric transition, which is consistent with a local electric fields-induced stiffening of the amorphous phase.

This hypothesis seems to be corroborated in the case of PVDF, which crystallizes from melt or solvent casting in the paralectric $\alpha$-phase similar to that of P(VDF-TrFE) above $T_{\mathrm{c}}$. It can be turned partially turned into the ferroelectric $\beta$ phase usually by mechanically stretching it. Dargaville et al. evidenced a much smaller modulus drop in 75/25 P(VDFTrFE) ( $\sim 20 \%$ drop) as compared to biaxially stretched PVDF $(\sim 70 \% \text { drop })^{22}$ Given that stretching only partially converts $\alpha$-PVDF to $\beta$-PVDF, it is anticipated that in the case of fully paraelectric (no local electric fields) $\alpha$-PVDF, the modulus drop would be even more pronounced.

Furthermore, this hypothesis is consistent with the overall reduced signal in dielectric measurements below the Curie transition that was ascribed to the oriented local electric fields reducing the amplitude of dipole motions. It seems

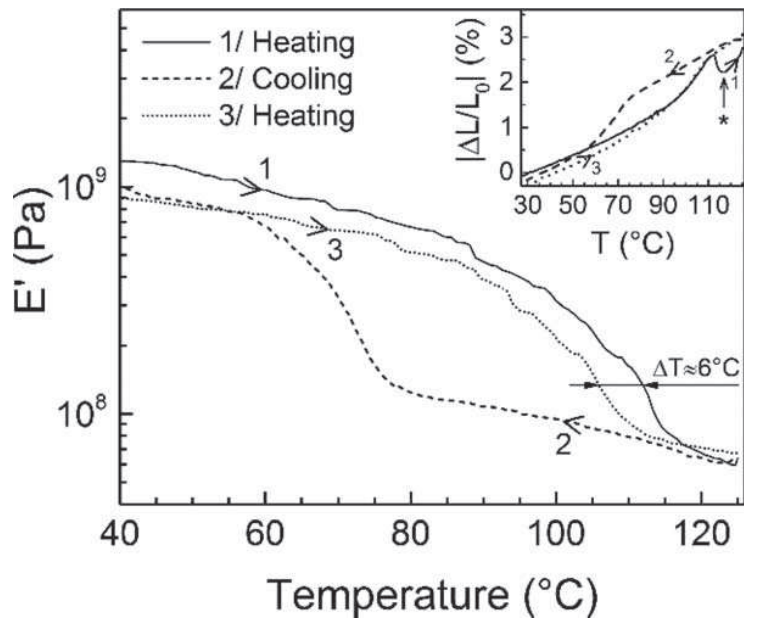

FIGURE 9 Evolution of initially poled P(VDF-TrFE) tensile storage modulus $E^{\prime}$ when heated and cooled through the Curie transition. Inset: associated dimension change relative to the initial length of the poled sample at $30{ }^{\circ} \mathrm{C}$. * indicates the remarkable shrinkage of the poled sample. 
rational that such constraints would mechanically translate into a higher storage modulus.

As previously mentioned by Legrand ${ }^{19}$ and Koizumi et al., ${ }^{23}$ the Curie transition goes along with a change in the crystalline phase density. A reversible sample dimension change is observed (inset of Fig. 9) due to the ferroelectric phase being more compact than the paraelectric one. At first glance, it seems that the poling-induced shift of $T_{\mathrm{c}}$ toward higher temperatures (evidenced in DSC, DDS, and DMA) is not observed on the sample dimension change. However, a steep $0.4 \%$ decrease in the length of the poled sample (shrinkage along the $z$ axis, indicated by the ${ }^{*}$ symbol in the inset of Fig. 9) is observed between $112{ }^{\circ} \mathrm{C}$ and $117^{\circ} \mathrm{C}$, after which the length increases back to a value consistent with the second and third ramps.

This shrinkage (to our knowledge not reported in literature) is counterintuitive as an increase in temperature is generally expected to lead to thermal expansion. A possible interpretation of this phenomenon resorts to the steep increase in molecular mobility at the Curie transition due to the progressive conversion of the ferroelectric to paraelectric phase, reducing the constraints on the amorphous phase. The remaining local electric fields could at some point induce a temporary state of "electrostriction" of the amorphous phase. This unstable state would then quickly evolve back to the normal depoled case, as the remaining ferroelectric phase further converts to the paraelectric one. However, the sample was poled perpendicular to its length so that this possible effect would be minimized in the tensile configuration. Further investigation of this shrinkage is thus required.

Finally, when comparing the first and third ramps below $T_{\mathrm{c}}$ it can be noted that the sample length has decreased $(\sim 0.07 \%)$ due to the increase in crystallinity (material densification) induced by the short annealing at temperatures $T_{\mathrm{c}}<T<T_{\mathrm{m}}$ at the end of the first ramp..$^{19,29,33}$ This increase in crystallinity is also believed to be responsible for the increase in tensile storage modulus on the glassy plateau of the depoled sample (Fig. 8).

\section{CONCLUSIONS}

The calorimetric, dielectric, and mechanical responses of highly piezoelectric 70/30 P(VDF-TrFE) (homogeneous $\mathrm{d}_{33}$ of $-19 \mathrm{pC} \mathrm{N}^{-1}$ ) were analyzed and correlated so as to assess the influence of poling on its mechanical properties and molecular mobilities.

An additional $14 \mathrm{~J} \mathrm{~g}^{-1}$ cohesive enthalpy of the ferroelectric crystalline phase induced by poling the material was determined in differential scanning calorimetry, which is approximately equal to the Curie enthalpy of unpoled solution-cast 70/ 30 P(VDF-TrFE)

Dynamic dielectric spectroscopy evidenced the $\gamma$ (local mobility), $\beta$ (free amorphous phase), $T_{\mathrm{g}-\mathrm{u}}$ (constrained amorphous phase), and $\alpha_{c}$ (most likely melting of secondary crystals at the surface of the main crystals) relaxations and the dielectric manifestation of the Curie transition. The dielectric response of the poled material was found to be globally reduced compared to the depoled one below the Curie transition.

Dynamic mechanical analysis also evidenced the four relaxations and the Curie transition of poled P(VDF-TrFE). The Curie transition manifests as a one decade drop in storage modulus upon heating, which is recovered upon cooling with the characteristic $50{ }^{\circ} \mathrm{C}$-hysteresis evidenced in calorimetric and dielectric measurements. A stiffening of the amorphous phase due to the local electric fields located in the ferroelectric crystalline phase was suggested, resulting in a "glassylike" state up to the Curie transition and the consequent disappearance of the local fields. The modulus drop at $T_{\mathrm{c}}$ is thought to be a sort of delayed viscoelastic transition rather than a consequence of a softening of the crystalline phase occurring at the ferro-paralectric transition.

The orientation of these local fields upon poling the material amplifies this phenomenon, resulting in a higher and more stable tensile storage modulus below the Curie transition and a weaker viscoelastic transition. This hypothesis also accounts for the lower dielectric signal of the poled sample below the Curie transition.

\section{REFERENCES AND NOTES}

1 H. Kawai, Jpn. J. Appl. Phys. 1969, 8, 975-976.

2 Y. Bar-Cohen, Q. Zhang, MRS Bull. 2008, 33, 173-181.

3 S. P. Beeby, M. J. Tudor, N. M. White, Meas. Sci. Technol. 2006, 17, R175-R195.

4 S. Crossley, R. A. Whiter, S. Kar-Narayan, Mater. Sci. Technol. 2014, 30, 1613-1624.

5 T. H. L. Nguyen, L. Laffont, J.-F. Capsal, P.-J. Cottinet, A Lonjon, E. Dantras, C. Lacabanne, Mater. Chem. Phys. 2015, 153, 195-201.

6 Q. Liu, X. Yin, C. Richard, J.-F. Capsal, J. Polym. Sci. Part B: Polym. Phys. 2016, 54, 1645-1657.

7 F. Bargain, P. Panine, F. Domingues Dos Santos, S. TencéGirault, Polymer (Guildf) 2016, 105, 144-156.

8 P. Martins, A. C. Lopes, S. Lanceros-Mendez, Prog. Polym. Sci. 2014, 39, 683-706.

9 M. Bohlén, K. Bolton, Phys. Chem. Chem. Phys. 2014, 16, 12929.

10 F. Oliveira, Y. Leterrier, J.-A. Månson, O. Sereda, A. Neels, A. Dommann, D. Damjanovic, J. Polym. Sci. Part B: Polym. Phys. 2014, 52, 496-506.

11 A. Lovinger, Science 1983, 220, 1115-1121.

12 J. B. Lando, W. W. Doll, J. Macromol. Sci. B 1968, 2, 205218.

13 A. J. Lovinger, D. D. Davis, R. E. Cais, J. M. Kometani, Polymer (Guildf) 1987, 28, 617-626.

14 I. L. Guy, A. Limbong, Z. Zheng, D. K. Das-Gupta, IEEE Trans. Dielectr. Electr. Insul. 2000, 7, 489-492.

15 K. Tashiro, M. Kobayashi, Polymer (Guildf) 1986, 27, 667676. 
16 K. J. Kim, G. B. Kim, Polymer (Guildf) 1997, 38, 4881-4889. 17 A. J. Lovinger, T. Furukawa, G. T. Davis, M. G. Broadhurst, Polymer (Guildf) 1983, 24, 1233-1239.

18 G. T. Davis, T. Furukawa, A. J. Lovinger, M. G. Broadhurst, Macromolecules 1982, 15, 329-333.

19 J. F. Legrand, Ferroelectrics 1989, 91, 303-317.

20 S. Dalle Vacche, F. Oliveira, Y. Leterrier, V. Michaud, D. Damjanovic, J.-A. E. Månson, J. Mater. Sci. 2012, 47, 47634774.

21 J. B. Ngoma, J. Y. Cavaille, J. Paletto, J. Perez, Polymer (Guildf) 1991, 32, 1044-1048.

22 T. R. Dargaville, M. Celina, P. M. Chaplya, J. Polym. Sci. Part B: Polym. Phys. 2005, 43, 1310-1320.

23 N. Koizumi, N. Haikawa, H. Habuka, Ferroelectrics 1984, 57, 99-119.

24 F. Bauer, US Patent, US Patent 4611260 A 1986.

25 S. Havriliak, S. Negami, J. Polym. Sci. C Polym. Symp. 1966, 14, 99-117.

26 T. Yagi, M. Tatemoto, J. Sako, Polym. J. 1980, 12, 209-223.

27 A. J. Lovinger, G. T. Davis, T. Furukawa, M. G. Broadhurst, Macromolecules 1982, 15, 323-328.

28 J. Y. Koo, I. T. Kim, J. T. Kim, W. K. Park, In: IEEE 1997 Annual Report Conference on Electrical Insulation and Dielectric Phenomena IEEE 1997; vol. 2: 370-373.

29 K. Koga, H. Ohigashi, J. Appl. Phys. 1986, 59, 2142.

30 G. Teyssedre, A. Bernes, C. Lacabanne, Thermochim. Acta 1993, 226, 65-75.

31 J. Menegotto, L. Ibos, A. Bernes, P. Demont, C. Lacabanne, Ferroelectrics 1999, 228, 1-22.

32 H. Ohigashi, N. Kagami, G. R. Li, J. Appl. Phys. 1992, 71, 506. 33 K. Koga, N. Nakano, T. Hattori, H. Ohigashi, J. Appl. Phys. 1990, 67, 965.
34 G. Teyssèdre, C. Lacabanne, Ferroelectrics 1995, 171, 125144.

35 K. Nakagawa, Y. Ishida, J. Polym. Sci. A-2 Polym. Phys. 1973, 11, 2153-2171.

36 R. A. Whiter, Y. Calahorra, C. Ou, S. Kar-Narayan, Macromol. Mater. Eng. 2016, 301, 1016-1025.

37 R. L. Moreira, P. Saint-Grégoire, M. Lopez, M. Latour, J. Polym. Sci. B Polym. Phys. 1989, 27, 709-722.

38 G. Teyssedre, A. Bernes, C. Lacabanne, J. Polym. Sci. Part B: Polym. Phys. 1995, 33, 879-890.

39 G. Teyssèdre, A. Bernès, C. Lacabanne, J. Polym. Sci. Part B: Polym. Phys. 1995, 33, 2419-2428.

40 S. Yano, J. Polym. Sci. A-2 Polym. Phys. 1970, 8, 1057-1072.

$41 \mathrm{H}$. Sasabe, S. Saito, M. Asahina, H. Kakutani, J. Polym. Sci. A-2 Polym. Phys. 1969, 7, 1405-1414.

42 K. Loufakis, B. Wunderlich, Macromolecules 1987, 20, 24742478.

43 L. Ibos, G. Teyssedre, A. Bernes, C. Lacabanne, In: Proc. SPIE 4017, Polymers and Liquid Crystals, 29, A. Wlochowicz, Ed.; International Society for Optics and Photonics 1999; 29-36.

44 M. Neidhöfer, F. Beaume, L. Ibos, A. Bernès, C. Lacabanne, Polymer (Guildf) 2004, 45, 1679-1688.

45 G. Teyssedre, A. Bernes, C. Lacabanne, J. Polym. Sci. Part B: Polym. Phys. 1993, 31, 2027-2034.

$46 \mathrm{H}$. Marand, A. Alizadeh, R. Farmer, R. Desai, V. Velikov, Macromolecules 2000, 33, 3392-3403.

47 C. Leonard, J. L. Halary, L. Monnerie, F. Micheron, Polym. Bull. 1984, 11, 195-202.

48 F. J. Baltá Calleja, C. Santa Cruz, A. González Arche, E. López Cabarcos, J. Mater. Sci. 1992, 27, 2124-2130.

49 Z. Xia, H.-J. Sue, A. J. Hsieh, J. W.-L. Huang, J. Polym. Sci. Part B: Polym. Phys. 2001, 39, 1394-1403. 